\title{
Um homem é um homem Brecht pela mão de Luís Miguel Cintra
}

\section{Maria Helena Serôdio}
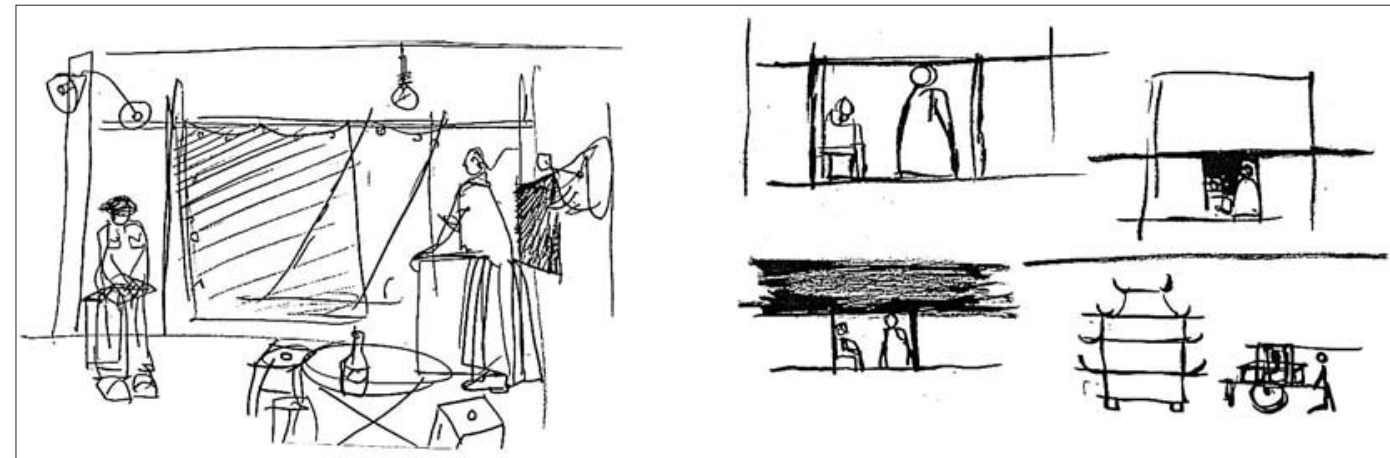

Esboços para a cenografia de Um homem é um homem, por Cristina Reis [cortesia da autora].
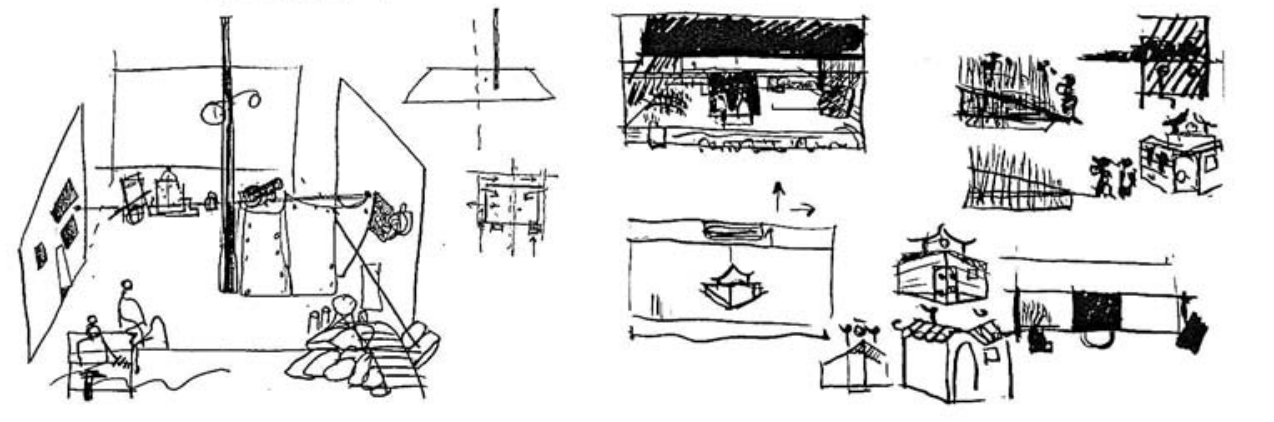

Escrevemos na "nota para a imprensa" que a atribuição do Prémio da Crítica 2005 ia (ex-aequo) para o espectáculo Um homem é um homem, do Teatro da Cornucópia, e acrescentávamos algumas das razões que justificavam o nosso voto: revelando uma extraordinária inventividade e uma exímia coerência artística, o espectáculo dava conta de uma brilhante leitura dramatúrgica, abordando a ironia e o sarcasmo na exposição dos mecanismos ideológicos da desumanização, tal como se desenvolvem no projecto estético de Brecht, aqui devolvido à sua específica marca modernista. Essa leitura surgia realizada artisticamente de forma superlativa pelas muitas contribuições criativas, admiravelmente orquestradas por uma prodigiosa encenação (e direcção de actores) de rara inteligência e sensibilidade.

Com uma temática tão candente - que aborda questões como a identidade individual, o sentido de alienação e a violência predadora da guerra -, o texto surgia em cena com uma grande força expressiva e infelizmente - com uma gritante actualidade. Tal circunstância tornou-se mais consistente com a decisão de fazer convergir a peça e o interlúdio - A cria de elefante -, criando desde logo uma respiração mais larga e, não obstante isso implicar uma maior ousadia em termos da duração do espectáculo, dai resultava também uma mais rica ampliação de reverberações internas. Por um lado, a escolha da versão de Um homem é um homem de 1953, a mais longa, permitia expor de forma mais elaborada quer a transformação do estivador em soldado até se tornar uma verdadeira máquina de guerra, quer o processo da loucura do sargento. Por outro lado, a introdução da pecinha A cria de elefante ou tudo se pode provar trazia uma dinâmica mais burlesca à cena, criava diferentes patamares de representabilidade e a verdade é que correspondia também à intenção inicial de Brecht que a publicara em 1927 juntamente com a primeira versão de Um homem é um homem.

Outro apuro ainda se prendeu ao tratamento dos textos e de outros materiais de incidência dramatúrgica: a qualidade das traduções - de António Conde e José Maria Vieira Mendes, respectivamente - e todo o enquadramento musical do espectáculo que correspondeu a uma selecção de João Paulo Santos executada ao piano por Nuno Lopes (o pianista que, curiosamente, coincidia no nome com um dos actores), criando momentos de deliciosa atmosfera festiva.

Em termos de diálogo Cornucópia-Brecht, é interessante recordar não apenas Terror e miséria no III Reich (1974) e Tambores na noite (1976), quando ainda a companhia tinha uma direcção partilhada entre Luis Miguel 


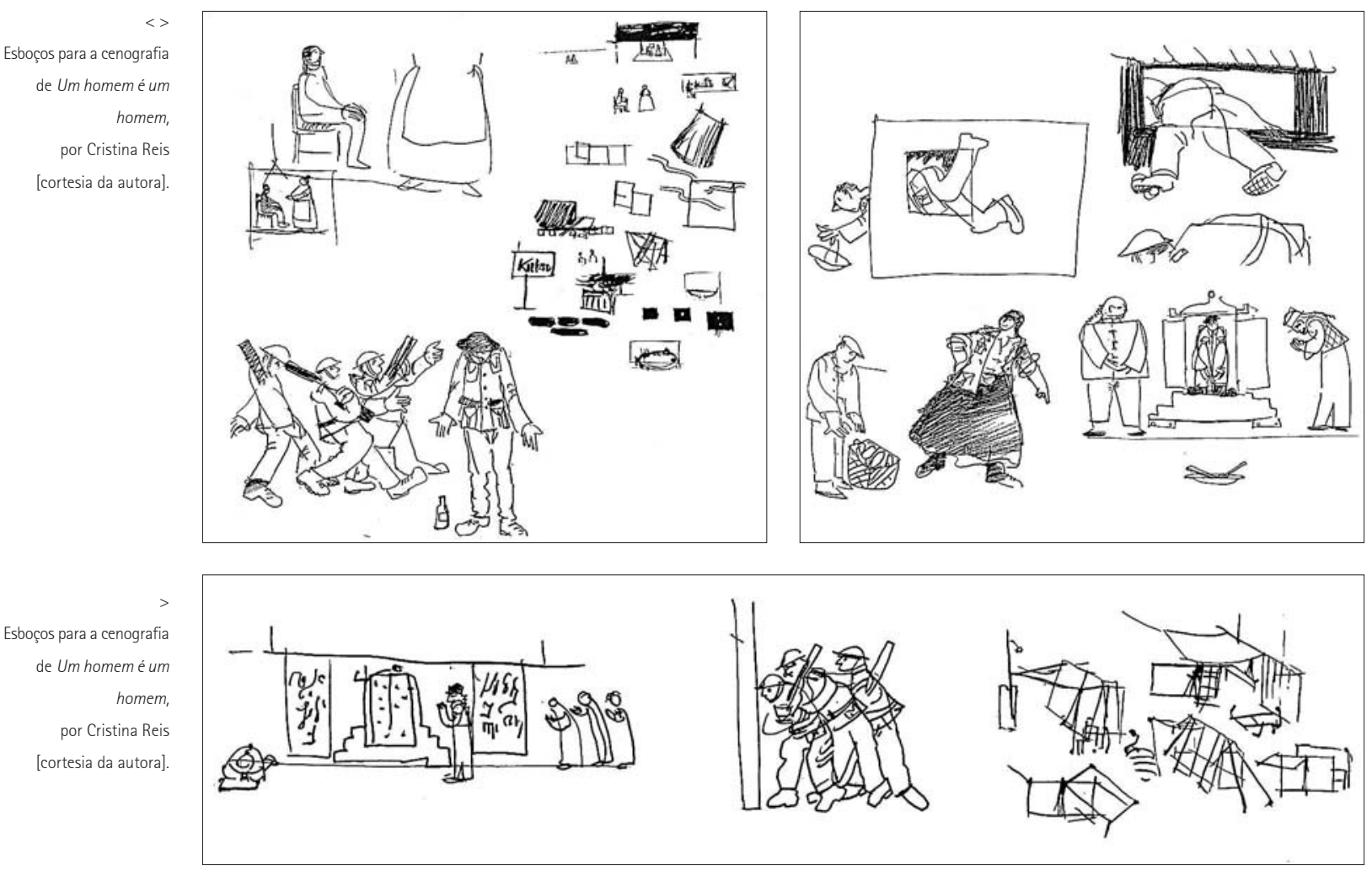

Cintra e Jorge Silva Melo, mas também o retorno ao autor alemão em 1983, quando Cintra seleccionou a peça radiofónica $A$ travessia aérea do oceano para um espectáculo - Oratória - que juntava a voz de Brecht a excertos de Gil Vicente e de Goethe para interrogar o momento histórico que atravessava nessa altura a sociedade portuguesa, mas também, muito provavelmente, a alma de alguns dos artistas que então integravam a companhia. 0 sentimento que parecia prevalecer era de uma clara disforia política e moral, um mal-estar obsessivamente denunciado, que se suspeitava - de forma aterradora - que seria dolorosamente irremovivel. Os textos estavam dramaturgicamente elaborados na sua deriva mais interrogativa e indecidivel, e revelavam-se cenicamente expostos num afectado descentramento de objectos em palco e numa amargurada verbalização por parte dos actores. Tratar-se-ia de, através desses três autores, sinalizar - de encontro às perplexidades então sentidas - as respostas que sucessivos universos ideológicos tinham vindo a engendrar: o cristianismo, o idealismo romântico e a dialéctica marxista. De todos eles parecia, todavia, esgotada a sua virtualidade redentora. Felizmente, porém, a sequência repertorial que a companhia foi posteriormente traçando devolvia-Ihes (e a nós espectadores, também) intermitências de alegria, ou de formas mais serenas de verbalizar ou interrogar esse malestar.

Apesar de durante mais de vinte anos a Cornucópia não ter voltado a Brecht, o certo é que outras modulações teatrais de "herdeiros" de Brecht foram ganhando forma e vida no espaço do Bairro Alto, como foi o caso de Edward Bond ou de Heiner Müller, em repetidas visitações. Com estes autores a companhia prosseguia a interpelação consistente de um repertório teatral através de formas interrogativas de, pelo teatro, falar da vida, da sua representabilidade e da eventual - e desejada - impugnação do status quo em termos estéticos, que o mesmo é dizer num procedimento artístico que opera consequências de ordem filosófica, política e vivencial.

Este regresso a Brecht, ele próprio, em 2005 surge depois de um ciclo de reflexão sobre o poder (que incluiu, em 2003 e 2004, peças de Shakespeare, Calderón e Heiner Müller, respectivamente Tito Andrónico, A vida é sonho e Anatomia Tito Fall of Rome), e na sequência de duas admiráveis construções teatrais sobre clássicos portugueses referidos à comédia: Filodemo, de Luis de Camões, e Esopaida, ou A vida de Esopo, de António José da Silva. Provando uma vez mais - na prática repertorial e nas opções artísticas mais fundas - a articulação produtiva entre a grande literatura, a sua capacidade de questionamento crítico, e a zona de afirmação - na vida de quem deles se abeira - de exigentes padrões estéticos. E essa é a singular marca de uma companhia de teatro que na cultura portuguesa vai instituindo patamares de cada vez mais elevada exigência dramatúrgica, figurativa, elocutória, interpretativa e musical, enfim, de formulação artística no seu mais amplo sentido.

A cenografia que Cristina Reis criou para Um homem é um homem representou um diálogo subtil entre as suas próprias formas de investir a cena - com parcimónia de efeitos, graça serena, inventividade artesanal - e os

"preceitos" que, em 1931, numa encenação desta peça em Berlim, Brecht inaugurava, de forma radical e modernista, como sendo o modo "épico" de representação. Uma paleta cromática de alguma austeridade, adereços mínimos em cena, o fingimento à vista, uma leve pintura da cara dos quatro soldados (evocando aspectos do cinema mudo de Buster Keaton a Charlot), as marcações cuidadosamente desenhadas, alguns quadros de imagem fortíssima com pouco mais do que o puro trabalho de corpos em constelações performativas eram, em resumo, os traços figurativos mais em evidência nesta criação da Cornucópia. 


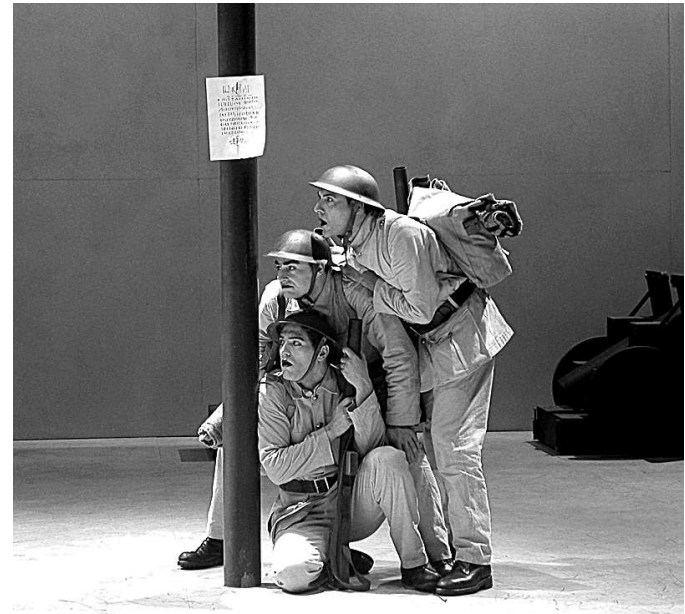

Nos vários planos da representação o trabalho dos actores revelou-se de um vigor e expressividade invulgares, com interpretações muito equilibradas de todo o elenco, que era vasto, mas, na sua maioria, já afeiçoado ao trabalho da companhia: Nuno Lopes, José Wallenstein, Ricardo Aibéo, Maria João Luis, Dinarte Branco, Duarte Guimarães, Pedro Lacerda, Luís Lima Barreto, Cláudia Jardim, Henrique Cardador, João Lizardo e Tiago Matias. Ao itinerário performativo especial de cada actor - na voz, na mímica, na gestualidade e nas marcações - sobrepunha-se uma realização cénica holistica que claramente decorria de uma visão artística de grande consistência e clareza interpretativa.

Com efeito, aliando a virtualidade fortemente crítica da peça (cruel, a vários títulos) a um jogo de graus diversos de cómico, o espectáculo revelava uma impressionante paleta de formulações interpretativas que comprovavam um entendimento seguro do texto e uma magnífica interpelação artística de hoje para as duas peças. E ai reside uma das forças mais eficientes da desconstrução operada por algumas das encenações de Luís Miguel Cintra: a de interferir nessa zona em que a inteligibilidade das situações mais se confunde com um difuso sentimento de um não-sei-quê invasor que nos assedia e que os espectáculos parecem trazer à tona para nos revitalizar o sentido crítico, mas também o prazer do reconhecimento de nós próprios.

É aqui que vale a pena relembrar o efeito de estranheza ou distanciação que marcou o modernismo de Brecht e trouxe futuro ao drama como fórmula artística de permanente vitalização do seu cânone. Não se trata, de facto, de mais uma "convenção", mas antes de pontos de apoio ou questionação para percebermos que o teatro só viverá da sua permanente refundação. E isso Luís Miguel Cintra não só compreendeu, mas operacionalizou em cena, mercê de uma judiciosa e amadurecida reflexão sobre o que fazer para cumprir o desafio de Brecht. Como escreveu no programa do espectáculo que trabalhava, nas suas palavras, "um texto genial":

Este teatro não é um produto cultural. É um trabalho. Um trabalho nosso e um trabalho para o espectador. Para gente que se divirta a pensar. Ai fica para quem quiser. Raras vezes no trabalho desta companhia se sentiu tanto o que é a dramaturgia. Cada momento da peça, cada gesto, cada entoação, cada objecto no palco, cada efeito de luz, nos pediu um pensamento e nos exigiu uma decisão. Concreta.

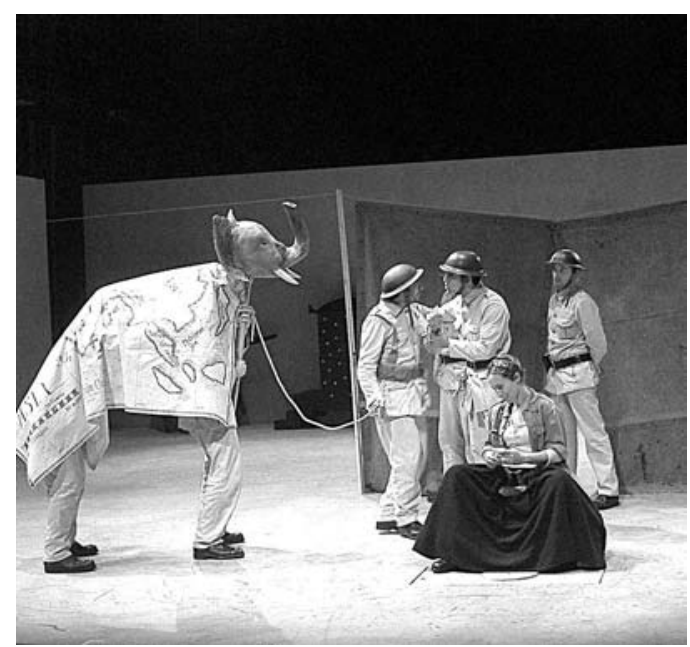

Detalhada. Sem medo nem cautelas. A responsabilidade que entregamos à sala exigiu-nos a nós outro trabalho. Talvez o da chamada "distanciação". Representar de outra maneira. Longe da identificação emotiva com as personagens a que nos vamos habituando como arte de bem representar. Não sei se conseguimos. Tratava-se de não vender espectáculo, de não seduzir, de não impor nenhuma opinião. Deixar campo de liberdade ao espectador. Sabemos que representar um texto assim é propor ao espectador um pensamento e é estar em cena com a responsabilidade que aos outros pedimos. (Cintra 2005: 5-6)

Para o fazer foi também necessário promover a reflexão, interrogação e pronunciamento de cada um dos que participaram nesta criação, pelo que o encenador confirmava no programa a invenção colectiva do espectáculo. E não se trata apenas de averbar nomes e procedimentos artísticos dos que na tradução, dramaturgia, encenação, cenografia, figurinos, desenho de luz, música, textos críticos e outras actividades - tanto artísticas como técnicas, tanto inventivas como de apoio - constam da ficha do espectáculo'. Trata-se também de perscrutar pela memória cultural, pelo saber actualizado - o que foi sendo feito em publicações e em palcos em torno deste autor e deste texto entre nós. Processos próprios de uma companhia de teatro que é alicerce sedutor da cultura que nos mantém espiritualmente vivos.

Neste diálogo e colaboração de Brecht e Cintra, com os colectivos que ambos movimentam e que Um homem é um homem cenicamente oficiou, relembremos palavras que surgiram no número anterior desta revista:

A eximia arquitectura deste espectáculo dava ainda testemunho da superação que aqui se atingiu como forma de reinventar Brecht: numa apoteótica construção de sentido que revela o que ele tem ainda para nos dizer, a nós que "viemos depois dele" e com ele tanto aprendemos e nos divertimos. (Serôdio 2005: 98)

\section{Referências bibliográficas}

CINTRA, Luis Miguel (2005), "Este espectáculo", Programa do espectáculo Um homem é um homem, Lisboa, Teatro da Cornucópia, pp. 3-6.

SERÔDIO, Maria Helena (2005), "Anatomia da desumanização", Sinais de cena, n. 4, Dezembro APCT / CET, Porto, Campo das Letras, pp. 94-98.
Um homem é um homem, de Bertolt Brecht, enc. Luis Miguel Cintra, Teatro da Cornucópia, 2005 (de baixo para cima: Nuno Lopes, Duarte Guimarães e Ricardo Aibéo), fot. Luis Santos.

Um homem é um homem, de Bertolt Brecht, enc. Luis Miguel Cintra, Teatro da Cornucópia, 2005 (Duarte Guimarães e Nuno Lopes, no elefante; Dinarte Branco, Henrique Cardador, Maria João Luis e João Lizardo), fot. Luis Santos.

'Para além dos tradutores, actores, criadores e outros colaboradores artisticos já aqui citados, são ainda de destacar: Daniel Worm d'Assumpção, Vasco Pimentel, Hugo Reis, Manuel Romano, Linda Gomes Teixeira, Luis Miguel Santos, Jorge Esteves, Rui Seabra e Amália Barriga, entre outros. 